DOI: https://doi.org/10.33330/jurteksi.v6i3.430

Available online at http://jurnal.stmikroyal.ac.id/index.php/jurteksi

\title{
PEMILIHAN TANAMAN BERDASARKAN KONDISI LAHAN DAN PERSYARATAN TUMBUH TANAMAN MENGGUNAKAN GABUNGAN METODE AHP DAN TOPSIS
}

\author{
Mi rajul Rifqi ${ }^{1}$, Dona ${ }^{1}$ \\ ${ }^{1}$ Sistem Informasi, Universitas Pasir Pengaraian \\ email: mirajulrifqi@gmail.com
}

\begin{abstract}
Most farmers are do'nt know what plants are suitable for planting on their land. This is due to the lack of knowledge of farmers regarding the suitability of land with the growing requirements of a crop. The lack of knowledge of farmers and the community about the evaluation of land suitability causes the cultivated plants do not produce optimally, because the conditions required by these plants are not in accordance with the conditions of the land that supports the growth of these plants. Seeing the importance of the process of selecting plants based on land suitability, while determining the selection of plants is still done only by looking at the experience of farmers who have not been tested. So the authors feel the need to make research to determine plants on land based on land suitability and plant growth requirements. The Analytical Hierarchy Process method is very suitable to be used to calculate the priority weight of each criterion because it is objective, which will later be used as a reference ranking by the TOPSIS method. With this research, it can determine the estate crops that will be planted on a land based on the level of land suitability and the requirements for growing plants that are alternative precisely, accurately and dynamically.
\end{abstract}

Keywords: DSS, AHP, TOPSIS

\begin{abstract}
Abstrak: Kebanyakan Petani masih banyak yang belum mengetahui tanaman apa yang cocok ditanaman di lahannya. Hal ini disebabkan karena kurangnya pengetahuan petani mengenai kesesuaian lahan dengan persyaratan tumbuh suatu tanaman. Lemahnya tingkat pengetahuan petani dan masyarakat tentang evaluasi kesesuaian lahan menyebabkan tanaman yang dibudidayakan tidak berproduksi optimal, karena syarat yang dibutuhkan tanaman tersebut belum sesuai dengan kondisi lahan yang mendukung pertumbuhan tanaman tersebut. Melihat pentingnya proses pemilihan tanaman berdasarkan kesesuain lahan, sedangkan penentuan pemilihan tanaman masih dilakukan hanya berdasarkan dengan melihat pengalaman petani yang belum teruji. Maka penulis merasa perlu membuat penelitian untuk menentukan tanaman pada lahan berdasarkan kesesuain lahan dan persyaratan tumbuh tanaman. Metode Analytical Hierarchy Process sangat cocok digunakan untuk menghitung bobot prioritas dari tiap kriteria karena bersifat obyektif, yang nantinya menjadi acuan perangkingan yang dilakukan dengan metode TOPSIS. Dengan adanya penelitian ini, maka dapat menentukan tanaman perkebunan yang akan ditanam pada suatu lahan berdasarkan tingkat kesesuaian lahan dan persyaratan tumbuh tanaman yang menjadi alternatif secara tepat, akurat dan dinamis.
\end{abstract}

Kata kunci: SPK, AHP, TOPSIS 
JURTEKSI (Jurnal Teknologi dan Sistem Informasi)

Vol. VI No. 3, Agus 2020, hlm. $201-208$

DOI: https://doi.org/10.33330/jurteksi.v6i3.430

Available online at http://jurnal.stmikroyal.ac.id/index.php/jurteksi

\section{PENDAHULUAN}

Penggunaan lahan pertanian dan perkebunan saat sekarang masih banyak petani yang belum mengetahui kesesuain dari lahan tersebut [1]. Petani masih banyak yang belum mengetahui tanaman apa yang cocok ditanaman di lahannya. Hal ini disebabkan karena kurangnya pengetahuan petani mengenai kesesuaian lahan dengan persyaratan tumbuh suatu tanaman. Kesesuaian lahan adalah penggambaran tingkat kecocokan sebidang lahan untuk suatu penggunaan tertentu. Kesesuaian lahan merupakan bagian dari evaluasi lahan [2]. Evaluasi kesesuaian lahan sangat diperlukan dalam perencanaan penggunaan lahan agar lahan dapat digunakan secara optimal, produktif dan berkelanjutan [3]. Lemahnya tingkat pengetahuan petani dan masyarakat tentang evaluasi kesesuaian lahan menyebabkan tanaman yang dibudidayakan tidak berproduksi optimal, karena syarat yang dibutuhkan tanaman tersebut belum sesuai dengan kondisi lahan yang mendukung pertumbuhan tanaman tersebut [4].

Melihat pentingnya proses pemilihan tanaman berdasarkan kesesuain lahan, sedangkan penentuan pemilihan tanaman masih dilakukan hanya berdasarkan dengan melihat pengalaman petani yang belum teruji. Maka penulis merasa perlu membuat penelitian untuk menentukan tanaman pada lahan berdasarkan kesesuain lahan dan persyaratan tumbuh tanaman dengan standar kriteria yang yang terdapat pada beberapa penelitian sebelumnya dengan gabungan metode Analytical
Hierarchy Process dan TOPSIS (Technique for Other Preference by Similarity to Ideal Solution).

Metode Analytical Hierarchy

Process sangat cocok digunakan untuk menghitung bobot prioritas dari tiap kriteria karena bersifat obyektif, yang nantinya menjadi acuan perangkingan yang dilakukan dengan metode TOPSIS [5]. Pendekatan TOPSIS dipilih karena memiliki beberapa kelebihan diantaranya [6]: (1) Menunjukkan suatu logika berpikir yang merepresentasikan pilihanpilihan manusia. (2) Menunjukkan suatu nilai skala alternatif terbaik dan terburuk secara simultan. (3) Menunjukkan perhitungan yang sederhana.

Tujuan dari penelitian adalah untuk menentukan tanaman perkebunan yang akan ditanam pada suatu lahan berdasarkan tingkat kesesuaian lahan dan persyaratan tumbuh tanaman yang menjadi alternatif secara tepat, akurat dan dinamis menggunakan gabungan metode AHP dan TOPSIS. Adapun secara Umum adalah memberikan informasi kepada petani alternatif pemilihan komoditi tanaman pangan yang sesuai dengan kemampuan tanah yang dilihat dari karakteristik lahan sehingga tanaman bisa berproduksi optimal, produktif dan berkelanjutan.

\section{METODE}

Penelitian yang menjadi acuan dalam lingkup metode yang digunakan pada penelitian ini adalah "Sistem Pendukung Keputusan Pemilihan Lahan Kelapa Sawit Dengan Metode Gabungan Dari Ahp, Profile 
JURTEKSI (Jurnal Teknologi dan Sistem Informasi)

Vol. VI No. 3, Agus 2020, hlm. $201-208$

DOI: https://doi.org/10.33330/jurteksi.v6i3.430

Available online at http://jurnal.stmikroyal.ac.id/index.php/jurteksi

Matching, Dan Topsis" [5] dan "Analysis of Criteria Influencing Contractor Selection Using TOPSIS Method" [9]. Penelitian Rifqi pada tahun 2016 membahas mengenai pemilihan lahan yang akan ditanami kelapa sawit. Penelitian ini menggabungkan tiga metode, yaitu AHP yang digunakan sebagai pemberian bobot setiap kriteria; profile matching yang digunakan untuk menghitung nilai selisih GAP antara kriteria dengan data kondisi lahan serta menghitung nilai tingkat kecocokan dari masing-masing alternatif yang telah ditentukan sehingga menghasilkan bobot yang obyektif; dan TOPSIS yang digunakan sebagai perangkingan alternatif.

Penelitian Alptekin pada tahun 2017 membahas mengenai pemilihan kontraktor menggunakan metode TOPSIS. Kriteria yang digunakan pada penelitian ini sebanyak dua belas kriteria. Proses evaluasi dan memilih kontraktor digunakan untuk memastikan kontraktor yang melamar betul-betul mampu untuk menyelesaikan suatu proyek yang dilelang, bukan hanya berdasarkan tawaran harga terendah.

Pada AHP, Bobot apriori merupakan bobot yang berasal dari hasil penilaian perbandingan berpasangan pada $A H P$ yang ditetapkan secara apriori, merefleksikan kondisi psikologi, dan kondisi sosial dari individu. Pada dasarnya merupakan modifikasi pembobotan $A H P$ yang dikembangkan oleh Saaty.

Langkah-langkah pembobotan tersebut adalah sebagai berikut :

a. Menentukan perbandingan berpasangan

$$
a_{i j}=\frac{w_{i}}{w_{j}} i, j=1,2, \ldots, n
$$

Dengan :
ISSN 2407-1811 (Print)

ISSN 2550-0201 (Online) $n=$ jumlah parameter yang dibandingkan

$w_{i}=$ bobot parameter ke- $i$

$a_{i j}=$ perbandingan bobot parameter ke$i$ dan paramenter ke- $j$

b. Menormalkan setiap kolom, yaitu dengan membagi setiap nilai pada kolom ke- $i$ dengan nilai terbesar ke- $i$.

$$
a_{i j}=\frac{a_{i j}}{\underset{j}{\max \left(a_{i j}\right)}}, \forall i, j
$$

c. Menjumlahkan nilai pada setiap kolom ke-i, yaitu

$$
\dot{a}_{i}=\sum_{j} \dot{a}_{i j}, \forall i
$$

d. Akhirnya bobot prior bagi setiap parameter ke- $i$, didapat dengan membagi setiap nilai $a_{i}$ dengan jumlah parameter yang dibandingkan (n), yaitu :

$$
\dot{w}_{i}=\frac{a_{i}}{n} \forall i
$$

Langkah-langkah perhitungan uji konsistensi (CR):

a. Kalikan seluru masukan kolom pertama matriks dengan bobot prioritas elemen pertama, kolom kedua dengan prioritas elemen kedua dan seterusnya.

b. Jumlahkan setiap barisnya.

c. Membagi setiap jumlah perbaris dengan prioritas relatif yang bersesuaian.

d. Jumlahkan hasil bagi diatas dan kemudian dibagi lagi dengan banyaknya elemen. Hasil proses ini disebuat dengan $\lambda$ maks atau eugen value.

e. Consistency index (CI) $C I=\left(\lambda_{\text {maks }} n\right) /(n-1)$ dimana $n$ merupakan banyak elemen.

f. Hitung nilai Consistency Rasio (RC)

$\mathrm{CR}=\mathrm{CI} / \mathrm{RI}$, dimana Random index 
Vol. VI No. 3, Agus 2020, hlm. $201-208$

DOI: https://doi.org/10.33330/jurteksi.v6i3.430

Available online at http://jurnal.stmikroyal.ac.id/index.php/jurteksi

(RI) merupakan nilai acak CI untuk suatu orde matriks.

Metode yang telah dipublikasikan harus ditunjukkan dengan referensi yang sesuai pada bagian daftar pustaka. Apabila terdapat modifikasi yang relevan, maka hal tersebut juga harus dijelaskan.

TOPSIS adalah metode MCDM yang didasarkan pada pengukuran jarak antara alternatif yang sedang dipertimbangkan dan dua alternatif referensi bipolar, ideal positif dan negatif [10]. TOPSIS standar terdiri dari enam langkah sebagai berikut:

1. Membangun Matriks Keputusan Ternormalisasi

$$
N=\left[\begin{array}{cccc}
\hat{x}_{11} & \hat{x}_{12} & \cdots & \hat{x}_{1 n} \\
\hat{x}_{21} & \hat{x}_{22} & \cdots & \hat{x}_{2 n} \\
\cdots & \cdots & \cdots & \cdots \\
\hat{x}_{m 1} & \hat{x}_{m 2} & \cdots & \hat{x}_{m n}
\end{array}\right]
$$

Di mana $\hat{x}_{j k}$ ditentukan dengan rumus di bawah ini:

$$
\hat{x}_{j k}=\frac{x_{j k}}{\sqrt{\sum_{j=1}^{m} x_{j k}^{2}}}
$$

Untuk $j=1, \ldots, m$ dan $k=1, \ldots, n$.

2. Menghitung Matriks Keputusan Ternormalisasi Terbobot

$$
\begin{gathered}
{\left[\begin{array}{cccc}
w_{1} \hat{x}_{11} & w_{2} \hat{x}_{12} & \cdots & w_{n} \hat{x}_{1 n} \\
w_{1} \hat{x}_{21} & w_{2} \hat{x}_{22} & \cdots & w_{n} \hat{x}_{2 n} \\
\cdots & \cdots & \cdots & \cdots \\
w_{1} \hat{x}_{21} & w_{2} \hat{x}_{22} & \ldots & w_{n} \hat{x}_{2 n}
\end{array}\right]=} \\
{\left[\begin{array}{cccc}
v_{11} & v_{12} & \cdots & v_{1 n} \\
v_{21} & v_{22} & \ldots & v_{2 n} \\
\cdots & \cdots & \ldots & \cdots \\
v_{m 1} & v_{m 2} & \ldots & v_{m n}
\end{array}\right]}
\end{gathered}
$$

3. Menentukan solusi ideal positif $A^{+}$ dan solusi ideal negatif $A^{-}$

$$
\begin{gathered}
A^{+}=\left(v_{1}^{+}, v_{2}^{+}, \ldots, v_{n}^{+}\right), \quad(8) \\
\text { Di mana } v_{k}^{+}=\max _{j}\left(v_{j k}\right), \\
\text { untuk } k=1, \ldots, n . \\
A^{-}=\left(v_{1}, v_{2}^{-}, \ldots, v_{n}^{-}\right)
\end{gathered}
$$

Di mana $v_{k}^{-}=\min _{j}\left(v_{j k}\right)$, untuk $k=1, \ldots, n$.

4. Menghitung jarak dari nilai tiap solusi ideal positif $\left(d_{j}^{+}\right)$dan solusi ideal negatif $\left(d_{j}{ }^{-}\right)$ke tiap alternatif:

$$
\begin{aligned}
& d_{j}^{+} \\
& =\sqrt[p]{\sum_{k=1}^{n}\left|v_{j k}-v_{k}^{+}\right|^{p}, \text { for } j} \\
& =1, \ldots, m, \\
& d_{j}^{-} \\
& =\sqrt[p]{\sum_{k=1}^{n}\left|v_{j k}-v_{k}^{-}\right|^{p}, \text { for } j} \\
& =1, \ldots ., m,
\end{aligned}
$$

Di mana $\mathrm{p}$ adalah koefisien jarak. Biasanya Euclidean distance digunakan pada TOPSIS, di mana $p=$ 2.

5. Menentukan kedekatan relative dari tiap aternatif ke tiap solusi ideal.

$$
\begin{aligned}
& S_{j}=\frac{d_{j}^{-}}{d_{j}^{+}+d_{j}^{-}}, \\
& \quad \text { for } j=1, \ldots, m,
\end{aligned}
$$

Di mana $0 \leq S_{j} \leq 1$. Semakin dekat alternatif $A_{j}$ ke solusi ideal positif, makin besar nilai $S_{j}$.

6. Meranking alternatif dengan urutan descending menggunakan $S_{j}$

\section{HASIL DAN PEMBAHASAN}

Permasalahan pada penelitian ini mencakup beberapa hal. Di antaranya adalah penentuan kriteria dan melakukan klasifikasi terhadap setiap kriteria yang ditentukan, Kriteria yang digunakan pada penelitian ini adalah sebagai berikut : 
JURTEKSI (Jurnal Teknologi dan Sistem Informasi)

Vol. VI No. 3, Agus 2020, hlm. $201-208$

DOI: https://doi.org/10.33330/jurteksi.v6i3.430

Available online at http://jurnal.stmikroyal.ac.id/index.php/jurteksi
Table 1. Kriteria Pemilihan jenis tanaman

\begin{tabular}{clc}
\hline No & Karakteristik lahan & Kode \\
\hline 1 & Temperatur Rerata & $\mathrm{C} 1$ \\
\hline 2 & Curah Hujan Tahunan & $\mathrm{C} 2$ \\
\hline 3 & pH Tanah & $\mathrm{C} 3$ \\
\hline 4 & C-Organik & $\mathrm{C} 4$ \\
\hline 5 & Kejenuhan Basa & $\mathrm{C} 5$ \\
\hline 6 & Kedalaman Efektif $(\mathrm{cm})$ & $\mathrm{C} 6$ \\
\hline
\end{tabular}

Setiap kriteria yang disebutkan di atas akan diklasifikasikan menjadi empat kelas, yaitu :

a. Kelas S1 : sangat sesuai (Highly Suitable), yaitu lahan yang tidak mempunyai pembatas yang berat untuk suatu penggunaan secara lestari atau hanya mempunyai pembatas tidak berarti dan tidak berpengaruh secara nyata terhadap produksi. Pada penelitian ini, kelas S1 diberi nilai 4.

b. Kelas S2 : cukup sesuai (Moderalty Suitable), yaitu lahan yang mempunyai pembatas-pembatas agak berat untuk suatu penggunaan yang lestari. Pembatas ini akan menurunkan

produktifitas/keuntungan dan perlu menaikkan masukan yang diperlukan. Pada penelitian ini, kelas S2 diberi nilai 3.

c. Kelas S3 : sesuai marjinal (Marginal Suitable), yaitu lahan yang mempunyai pembatas-cpembatas berat untuk untuk suatu penggunaan lestari. Pada penelitian ini, kelas S3 diberi nilai 2. d. Kelas N : tidak sesuai (Not Suitable ), yaitu lahan yang mempunyai pembatas sangat berat sehingga sangat kecil kemungkinan digunakan untuk suatu penggunaan lestari. Pada penelitian ini, kelas $\mathrm{N}$ diberi nilai 1 .

Nilai rating alternatif, diberikan pada tabel berikut :

Table 2. Nilai rating alternatif lahan

\begin{tabular}{ccccccc}
\hline & C1 & C2 & C3 & C4 & C5 & C6 \\
\hline A1 & 3 & 3 & 3 & 4 & 4 & 4 \\
\hline A2 & 3 & 3 & 3 & 3 & 4 & 3 \\
\hline A3 & 1 & 4 & 1 & 3 & 4 & 3 \\
\hline A4 & 2 & 3 & 2 & 4 & 1 & 4 \\
\hline A5 & 1 & 2 & 4 & 4 & 1 & 3 \\
\hline
\end{tabular}

Berdasarkan data di atas maka dihitunglah bobot kriteria yang digunakan pada penelitian ini menggunakan metode Analytical Hierarchy Process seperti di bawah ini:

1. Membuat matrik perbandingan berpasangan

Table 3. Matrik Perbandingan Berpasangan

\begin{tabular}{ccccccc}
\hline & c1 & c2 & c3 & c4 & c5 & c6 \\
\hline c1 & 1,000 & 2,000 & 3,000 & 4,000 & 6,000 & 7,000 \\
\hline c2 & 0,500 & 1,000 & 2,000 & 3,000 & 4,000 & 7,000 \\
\hline c3 & 0,333 & 0,500 & 1,000 & 3,000 & 5,000 & 5,000 \\
\hline c4 & 0,250 & 0,333 & 0,333 & 1,000 & 3,000 & 2,000 \\
\hline c5 & 0,167 & 0,250 & 0,200 & 0,333 & 1,000 & 2,000 \\
\hline c6 & 0,143 & 0,143 & 0,200 & 0,500 & 0,500 & 1,000 \\
\hline Jlh & 1,393 & 2,226 & 3,733 & 7,833 & 13,50 & 17,00
\end{tabular}

2. Kemudian menghitung bobot 
DOI: https://doi.org/10.33330/jurteksi.v6i3.430

Available online at http://jurnal.stmikroyal.ac.id/index.php/jurteksi

Tabel 4. Matrix Bobot

\begin{tabular}{ccccccccc}
\hline & $\mathrm{c} 1$ & $\mathrm{c} 2$ & $\mathrm{c} 3$ & $\mathrm{c4}$ & $\mathrm{c5}$ & $\mathrm{c6}$ & $\mathrm{vp}$ & wsm \\
\hline $\mathrm{c1}$ & 0,718 & 0,898 & 0,804 & 0,511 & 0,444 & 0,412 & 0,631 & 3,886 \\
\hline $\mathrm{c} 2$ & 0,359 & 0,449 & 0,536 & 0,383 & 0,296 & 0,412 & 0,406 & 2,547 \\
\hline $\mathrm{c3}$ & 0,239 & 0,225 & 0,268 & 0,383 & 0,370 & 0,294 & 0,297 & 1,903 \\
\hline $\mathrm{c} 4$ & 0,179 & 0,150 & 0,089 & 0,128 & 0,222 & 0,118 & 0,148 & 0,926 \\
\hline $\mathrm{c5}$ & 0,120 & 0,112 & 0,054 & 0,043 & 0,074 & 0,118 & 0,087 & 0,528 \\
\hline $\mathrm{c6}$ & 0,103 & 0,064 & 0,054 & 0,064 & 0,037 & 0,059 & 0,063 & 0,388 \\
\hline
\end{tabular}

3. Kemudian menghitung ratio konsistensi sebagai berikut:

$$
\begin{array}{cr}
\text { lambda } & \\
\text { max } & 6,225 \\
\text { ci } & 0,045 \\
\text { cr } & 0,036231
\end{array}
$$

Berdasarkan hasil di atas, maka matrik perbandingan berpasangan bisa diterima. Dan bobot kriteria diperoleh berdasarkan kolom vp pada table 4.

4. Berdasarkan nilai alternatif pada tabel 2, maka dilakukan normalisasi menggunakan metode TOPSIS dengan hasil matrik keputusan normalisasi seperti yang ditunjukkan pada tabel 5 berikut :

Table 5. Matrik keputusan normalisasi

\begin{tabular}{llllll}
\hline 0,612372 & 0,437595 & 0,480384 & 0,492366 & 0,565685 & 0,520756 \\
\hline 0,612372 & 0,437595 & 0,480384 & 0,369274 & 0,565685 & 0,390567 \\
\hline 0,204124 & 0,58346 & 0,160128 & 0,369274 & 0,565685 & 0,390567 \\
\hline 0,408248 & 0,437595 & 0,320256 & 0,492366 & 0,141421 & 0,520756 \\
\hline 0,204124 & 0,29173 & 0,640513 & 0,492366 & 0,141421 & 0,390567
\end{tabular}

5. Membangun matrik keputusan normalisasi terbobot dengan hasil seperti yang ditunjukkan pada tabel 6 berikut :

Table 6. Matrik keputusan normalisasi terbobot

\begin{tabular}{|l|r|r|r|r|r|}
\hline 0,386485 & 0,177585 & 0,142453 & 0,072709 & 0,049008 & 0,032981 \\
\hline 0,386485 & 0,177585 & 0,142453 & 0,054532 & 0,049008 & 0,024736 \\
\hline 0,128828 & 0,23678 & 0,047484 & 0,054532 & 0,049008 & 0,024736 \\
\hline 0,257657 & 0,177585 & 0,094969 & 0,072709 & 0,012252 & 0,032981 \\
\hline 0,128828 & 0,11839 & 0,189938 & 0,072709 & 0,012252 & 0,024736 \\
\hline
\end{tabular}


DOI: https://doi.org/10.33330/jurteksi.v6i3.430

Available online at http://jurnal.stmikroyal.ac.id/index.php/jurteksi

6. Menghitung solusi ideal positif dan negatif sebagai berikut :

Table 7. solusi ideal positif dan negatif

\begin{tabular}{ccc}
\hline & positif & negatif \\
\hline c1 & 0,386485 & 0,128828 \\
\hline c2 & 0,23678 & 0,11839 \\
\hline c3 & 0,189938 & 0,047484 \\
\hline c4 & 0,072709 & 0,054532 \\
\hline c5 & 0,049008 & 0,012252 \\
\hline c6 & 0,032981 & 0,024736 \\
\hline
\end{tabular}

7. Langkah selanjutnya adalah menghitung jarak dari nilai tiap solusi ideal positif dan solusi ideal negatif ke tiap alternatif.

Table 8. jarak solusi ideal positif dan

\begin{tabular}{ccc}
\multicolumn{3}{c}{ negatif } \\
\hline & positif & negatif \\
\hline A1 & 0,075887 & 0,284006 \\
\hline A2 & 0,078468 & 0,283304 \\
\hline A3 & 0,29509 & 0,123965 \\
\hline A4 & 0,174559 & 0,150844 \\
\hline A5 & 0,286046 & 0,143608 \\
\hline
\end{tabular}

8. Menentukan kedekatan relative dari tiap alternatif ke tiap solusi ideal. Tahapan ini merupakan penilaian akhir dari seluruh proses perangkingan alternatif menggunakan gabungan metode AHP dan TOPSIS. Hasil perangkingan ditunjukkan pada tabel 9 berikut :

Table 9. Hasil Perangkingan

\begin{tabular}{cc}
\hline $\mathbf{A 1}$ & 0,78914 \\
\hline $\mathbf{A 2}$ & 0,783101 \\
\hline $\mathbf{A 3}$ & 0,295819 \\
\hline $\mathbf{A 4}$ & 0,463561 \\
\hline $\mathbf{A 5}$ & 0,334242 \\
\hline
\end{tabular}

\section{SIMPULAN}

Pemilihan tanaman perkebunan dengan menggunakan gabungan metode AHP dan TOPSIS bisa dilakukan. Metode AHP bisa memberikan bobot pada kriteria yang digunakan pada penelitian ini berdasarkan tingkat perbandingan berpasangan. Hasil dari pembobotan kriteria tersebut dijadikan sebagai bobot pada perhitungan perangkingan alternatif menggunakan metode TOPSIS. Berdasarkan pengujian yang telah dilakukan, diperoleh hasil perhitungan sistem yang sesuai dengan hasil perhitungan manual. Sistem Pendukung Keputusan yang dibangun ini juga bersifat fleksibel karena data alternatif dan parameter beserta aturannya dapat ditambah, diubah, dan dihapus sehingga nilai akhir untuk masing-masing pengambilan keputusan pun dapat berubah.

\section{DAFTAR PUSTAKA}

[1] Yogi Rafika. 2015. Kesesuaian Lahan tanaman kopi di Politeknik Pertanian Negeri Payakumbuh. Jurnal nasional ecopedon JNEP vol. 2 no. 1 (2015)56-60

[2] Wibowo Yogi. 2009. Evaluasi kesesuaian Lahan untuk Perkebunan Tanaman Teh di Kecamatan Bandar Kabupaten Batang. Skripsi. Surakarta : Universitas Muhammadiyah Surakarta

[3] Yatno Edi. 2016. Kriteria Kesesuaian Lahan untuk Tanaman Kakao di Kabupaten 
Vol. VI No. 3, Agus 2020, hlm. $201-208$

DOI: https://doi.org/10.33330/jurteksi.v6i3.430

Available online at http://jurnal.stmikroyal.ac.id/index.php/jurteksi

Kolaka dan Kolaka Timur, Sulawesi Tenggara. Tesis. Bogor : Institut Pertanian Bogor

[4] Sandri Fitriawati. 2015. Kesesuaian Lahan Tanaman Kelapa di Lahan Politeknik Pertanian Negeri Payakumbuh. Jurnal Nasional EcopedonJNEP Vol. 2 No.1 (2015) 43-47

[5] Rifqi Mi rajul. 2016. Sistem Pendukung Keputusan Pemilihan Lahan Kelapa Sawit Dengan Metode Gabungan dari AHP, Profile Matching, dan TOPSIS. Tesis. Yogyakarta : Universitas Gadjah Mada.

[6] Yayin, Y. D. 2011. "Integrasi Pendekatan Fuzzy Analytic Network Process (FANP) dan Technique For Order Preference By Similarity To Ideal Solution (TOPSIS) untuk Pemilian Logistic Service Provider (Studi Kasus: PT. EPT)". Tesis. Surabaya: Magister Teknik Industri ITS.

[7] Rizky, N., Arysanti, D., Adyatma, S. 2017. Evaluasi Kesesuaian Lahan untuk Tanaman Kelapa Sawit di Kecamatan Batang Alai Utara, Kabupaten Hulu Sungai Tengah. JPG (Jurnal Pendidikan Geografi) Volume 4 No 4 Juli 2017 Halaman 9-22

[8] Hasanah Fitriana Uswatun. 2012. Evaluasi Kesesuaian
Lahan untuk Tanaman Cengkeh (Eugenia aromatica L.) di Kecamatan Jatinom Kabupaten Klaten. Skripsi. Surakarta : Universitas Muhammadiyah Surakarta

[9] Alptekin Orkun., \& Alptekin Nesrin. 2017. Analysis of Criteria Influencing Contractor Selection Using TOPSIS Method. IOP Conf. Series: Materials Science and Engineering $245 \quad$ (2017) 062003

[10] Wachowicz, T., Baszczyk, P. 2013. "TOPSIS Based Approach to Scoring Negotiating Offers in Negotiation Support Sistems". Group Decision and Negotiation, no. 6, vol. 22, pp. 1021-1050 